\title{
O CÓDICE DE HAMBURGO DESVENDA O PRIMEIRO MAPA DE PORTUGAL?
}

\author{
MARIA FERNANDA ALEGRIA ${ }^{1}$
}

Foi publicado no final de 2010 um importante livro de Suzanne Daveau com o título Um Antigo Mapa de Portugal (c. 1525). Reconstituição a partir do Códice de Hamburgo. Acompanhei a concepção e as sucessivas fases de remodelação desta obra, que foi dedicada a Orlando Ribeiro, durante os cerca de 10 anos que ela levou a construir. Como a autora refere, logo na apresentação, o interesse pelo Códice de Hamburgo começou em 1999, quando quatro investigadores ibéricos foram contactados pelos editores americanos de The History of Cartography para prepararem o contributo português para o $3 .^{\circ}$ volume desta colectânea, Cartography in the European Renaissance, editado apenas em 2007. Foi um longo percurso que permitiu, por fim, colocar à disposição dos interessados um valioso contributo sobre aspectos desconhecidos da História da Cartografia portuguesa.

O texto, com 359 páginas, comporta duas partes, a seguir à introdução, que inclui uma apresentação em 3 línguas: a primeira parte relativa ao códice (p. 21-121), a segunda sobre o mapa (p. 122-229), a que se junta uma terceira parte de documentos (p. 231-359). Na primeira parte estudam-se, em três capítulos, aspectos específicos do próprio códice, preservado na Staats- und Universitätsbibliothek de Hamburgo, com a cota Codex 136 in scrinium. Na segunda, também com três capítulos, reconstitui-se o mapa, a partir do qual o códice foi construído, e analisam-se aspectos relativos às condições da sua preparação.

Com uma apresentação cuidada, muitas figuras a preto e branco, ilustrações a cores e um CD-Rom, que facilita a consulta e utilização dos mapas e dos extensos anexos, temos na introdução uma explicação pormenorizada da estrutura do texto, o que facilita muito a sua consulta. Por isso, mais do que descrever o livro importa realçar o que ele traz de novo.

\section{NOVIDADES TRAZIDAS PELO ESTUDO DO CÓDICE DE HAMBURGO}

Um livro desta natureza permite leituras de natureza diversificada. Haverá as que interessam mais ao historiador, ao cartógrafo ou ao matemático, talvez ao bibliógrafo ou ao documentalista. As impressões que aqui se deixam são as que mais dizem aos geógrafos, particularmente aos interessados pela História da Cartografia.

Recebido: Junho 2011. Aceite: Setembro 2011.

1 Investigadora do Centro de Estudos Geográficos. E-mail: mfalegria@netcabo.pt 
Um mapa de Portugal de c. 1525? Esta é porventura a descoberta mais relevante. A autora mostra neste livro que existiu um mapa de Portugal, que antecede em cerca de 35 anos o espécime cartográfico que era até agora considerado o mais antigo de Portugal - o mapa de Fernando Álvaro Seco, de 1561. Embora o mapa propriamente dito não tenha sido encontrado, foi possível, com um paciente e cuidadoso trabalho, reconstituir as suas características. É verdade que a hipótese de o Códice de Hamburgo (ou seja, a lista toponímica com o registo da latitude e da longitude de quase 1500 lugares), só poder ter sido elaborado a partir de um mapa pré-existente tinha já sido avançada por Kevin Kaufman - um jovem americano que preparou sobre ele uma tese, sob a orientação do prestigiado David Woordward -, mas este investigador deixou muitos aspectos por esclarecer. Um deles diz respeito ao enigmático sistema de notação das coordenadas utilizado no códice, cuidadosamente descrito e deslindado no capítulo 2 do livro, a que se fará especial menção.

A decifração do modo como foram registadas as coordenadas de tantos lugares, a maior parte das quais relativamente correcta (embora a lista dos erros cometidos se tivesse revelado preciosa ajuda para reconstituir o processo de construção do mapa), permitiu perceber que elas não podiam ter sido determinadas astronomicamente. O mapa foi construído a partir de técnicas de medição de distâncias em léguas, compiladas ao longo de alguns dos itinerários mais percorridos. Esta descoberta enfatiza a importância da cartografia terrestre no século XVI, que tem sido menosprezada pela maior parte dos investigadores portugueses, face à produção náutica coeva.

Vale a pena lembrar que a precisão das medições de latitude efectuadas a bordo dos navios era então fraca. Na melhor das hipóteses da ordem de 1/6 de grau (10 minutos), e com uma variabilidade acentuada entre os resultados obtidos simultaneamente por diversos observadores, como demonstraram as experiências comparativas, repetidamente efectuadas por D. João de Castro durante a sua viagem de Lisboa a Goa, em 1538, aspecto recordado por Teixeira da Mota em 1957. Este investigador lembrou ainda, no mesmo texto, que a medição das latitudes servia apenas aos marinheiros como "simples conhecenças locais", ou para "controlar a estima do caminho percorrido" no sentido norte-sul. Portanto, o rigor da determinação das latitudes no mar era reduzido. Seriam, na realidade, os cosmógrafos terrestres, e não náuticos, que mais progressos iriam desenvolver para a colocação exacta dos lugares nos mapas, com ou sem utilização das coordenadas geográficas.

Numa altura em que os mandamentos da Igreja e as crenças decorrentes do modelo cosmográfico se confrontavam, e quando a determinação correcta da longitude não era ainda possível, acarretando esse desconhecimento longas e penosas negociações entre Portugal e Espanha relativas à posse das Molucas por exemplo, perceber o modo como os mapas terrestres enfrentavam esses problemas teosóficos e práticos é uma discussão muito interessante. Para isso a autora socorreu-se de fontes muito variadas: da consulta de mapas contemporâneos de outros países (França, Boémia), de fontes escritas diversas, algumas, até, aparentemente desligadas do problema das coordenadas, como é o caso de alguns dos textos de Gil Vicente.

Os enigmas que este livro resolve são, de facto, muitos. Tratemos agora da data do códice e do seu autor, aspectos relacionados entre si, antes de tentarmos perceber como se conseguiram decifrar as coordenadas.

A data do códice. Segundo Moreira de Sá (1956), foi no "dia da Trindade do ano de 1526, a 27 de Abril" que D. Francisco de Melo proferiu uma fala oficial em Almeirim "quando deitaram o capelo de Cardeal ao Ilustre Infante D. Afonso, Cardeal diácono do título de S. Brás". O Infante, nascido em 23 de Abril de 1509, acabava então de completar os 17 anos e teria recebido o códice de presente, nesse festivo dia 27 de Abril de 1526, como se documen- 
ta no capítulo IV. Neste capítulo figuram também outros argumentos sobre a data da oferta e muitas informações sobre a personalidade do Cardeal D. Afonso e o ambiente da corte.

$O$ autor do ilustrado códice. A primeira hipótese, colocada por Suzanne Daveau em 2001, de ter sido António de Ataíde (c. 1500-1563) é agora recusada com vários argumentos (p. 143-146).

Dois outros potenciais autores, Pedro Margalho (1474-1556) e João de Barros (1496-1570), são também eliminados. O primeiro, depois de ter recebido formação em França (1490-1510) e de ter ensinado em Espanha (1525-1529), só regressou a Portugal no começo de 1530. Além disso, os seus conhecimentos tinham pendor muito teórico. A mesma impressão de que a teoria ultrapassava o saber prático é aplicada a João de Barros.

Quanto a Pedro Nunes (1502-1578), considerado geralmente o mais famoso matemático português, só em 1529 voltou de Espanha, onde tinha casado e estudado. Não estaria, portanto, instalado ainda em Lisboa, enquanto se preparava o mapa corográfico de Portugal. As suas relações docentes com os irmãos de D. João III são também, sem dúvida, posteriores à oferta do códex a D. Afonso.

A autora chega assim, "por eliminação de partes" (p. 146), à hipótese de ter sido D. Francisco de Melo (1490-1536) o promotor da oferta do mapa a D. Afonso e, provavelmente, o autor do códice. Residente na Corte desde que voltou de Paris (em 1520 ou 1521), até à sua morte em Évora (em 1536), conviveu longamente com D. Afonso. Mas a figura de Francisco de Melo continua mal conhecida. Apesar de haver registo de vários testemunhos elogiosos dos seus contemporâneos, e de algumas referências em estudos dos séculos XVIII e XIX, nenhuma pesquisa recente lhe foi consagrada. Admite-se que possa ter conhecido Oronce Fine em Paris, o autor de um célebre mapa corográfico da França de 1525. Antes disso, sabe-se da participação activa de D. Francisco de Melo na organização da Junta de Elvas - Badajoz, em 1524, sobre a qual há abundante documentação publicada. Por exemplo, há notícia de que o Rei o tinha encarregado de lhe escrever particularmente sobre o que se passava nas reuniões da Junta, cada vez que julgasse necessário, o que ele faz usando uma liberdade de expressão, e um tom, que indiciam alguma proximidade ao soberano, ao mesmo tempo que revela muita perspicácia nas apreciações que faz. Nos anos seguintes, e até à sua morte em 1536, a sua actividade oficial está relativamente bem documentada.

Três decénios mais tarde (c. 1557), o cartógrafo Lopo Homem, ao criticar as inovações no desenho dos mapas náuticos, introduzidas entretanto por Pedro Nunes, afirmará que Francisco de Melo era então "o mais ciente em Matemática e Cosmografia que fosse em Portugal”, colocando-o assim, implicitamente, acima de Pedro Nunes (L. de Matos, 1952, p. 102).

O processo de notação das coordenadas é motivo de inesperadas descobertas, mesmo para os matemáticos portugueses e espanhóis que foram consultados por Suzanne Daveau.

Antes de mais, relembre-se que o Códice de Hamburgo reúne as coordenadas de perto de 1500 lugares e que é usado o mesmo tipo de fracções para registar a latitude e a longitude. Por outro lado, como já se referiu, todos os cartógrafos que observaram o códice concordam que seria impossível determinar astronomicamente tão elevado número de localizações. Já em 1956 quatro investigadores da Universidade de Coimbra puseram a hipótese de as coordenadas terem sido medidas num mapa, mas não foram capazes de decifrar a notação usada no códice.

O raciocínio de Suzanne Daveau, que ela diz estar baseado em "reflexões e observações muito simples", é deveras curioso. Vale a pena segui-lo:

a) No começo do século XVI, a técnica de determinação e notação das coordenadas não podia basear-se em cálculos complexos mas, provavelmente, em medições de realização fácil. 
b) A complexidade da notação usada no códice não parece resultar de grande prática em contas mas, pelo contrário, de fraco à vontade na expressão dos resultados. Essa complexidade resultaria mais do seu carácter empírico do que de uma criação sábia, nova e sofisticada.

c) Embora o uso das fracções complexas tenha desaparecido actualmente da linguagem escrita, ele mantém-se nalgumas expressões orais populares. Em Vale de Lobos, onde Suzanne Daveau vive, apenas a $20 \mathrm{~km}$ de Lisboa, ainda se pode ouvir pedir, nalgumas lojas, "meio arrátel" de manteiga (250 gramas) ou "uma quarta" (125 gramas) ou, até, "meia quarta" (cerca de 65 gramas).

d) Para medir as coordenadas no mapa, a partir do qual o índice foi concebido, é provável que se tenham usado técnicas então correntes entre os marinheiros: a medição seria feita no mapa com um compasso e numerada graças a um "tronco" anexo. Explicações cuidadas e minuciosas sobre o número de troncos e a sua posição face ao mapa são apresentadas no livro, mas não vão ser agora descritas.

e) O processo de notação usado por Ptolomeu na Geografia tem semelhanças com o que aparece no Códice de Hamburgo: o algarismo que indica o número de graus de longitude ou de latitude encontra-se seguido, à direita, por uma ou por várias fracções. O número de fracções varia entre 1 e 3 na Geografia, e entre 0 e 2 no Códice de Hamburgo. Mas o sistema de fracções usado no códice é bastante mais complexo do que na Geografia.

f) Os algarismos da primeira coluna representam graus e os das duas colunas à direita subdivisões do grau, sob a forma de uma ou de duas fracções - ou "quebrados" como se dizia então. Essas fracções podem ter dois ou três elementos.

g) Veja-se agora o caso da notação da latitude de Lisboa, que é registada assim: 39 1/6 $1 / 3$.

Como se devem ler estes números? A latitude de Lisboa é de $39^{\circ}$ mais um sexto de grau (ou seja 10'), mais um terço de um sexto de grau (ou seja um terço de 10', isto é 3,3). A latitude é portanto de $39^{\circ}$ mais $10^{\prime}$ mais $3,3^{\circ}=39^{\circ} 13,3^{\prime}$.

O que é importante registar - e essa foi uma descoberta que parecia simples, mas que ninguém tinha feito antes de Suzanne Daveau - é que no códice não se escreveu 1/3 de 1/6. Subentendeu-se que 1/6 estava presente sem estar escrito, o que $\mathrm{S}$. Daveau regista no livro como (6). Ou seja, as notações de coordenadas devem ler-se sempre de modo a que se tenha sempre em conta uma fracção oculta, que é igual à que figura na $2^{\mathrm{a}}$ coluna.

Ter encontrado a chave de leitura das fracções aparentemente simples da $3^{\text {a }}$ coluna permitiu a decifração exacta das coordenadas registadas no códice e a reconstituição completa do mapa que lhe serviu de base. Imagens do que ele teria sido podem observar-se nos documentos finais do livro. Os mapas A, em versões mudas e com topónimos e em duas escalas, reconstituem o original; os mapas B, com a transcrição dos lugares sobre um fundo moderno, permitem uma imagem, mais próxima da realidade contemporânea, do que seria o conhecimento do território português cerca de 1525 .

\section{DIFICULDADES E DÚVIDAS}

Há que reconhecer que a leitura deste texto exige algum esforço. Para começar, pela dimensão. Não é de ânimo leve que alguém se abalança a digerir mais de 350 páginas, gran- 
des (quase em tamanho $\mathrm{A}_{4}$ ) e bastante densas. Depois, a diversidade de assuntos tratados exige que o leitor tenha uma preparação bastante sólida, ou pelo menos interesses variados, em História, Geografia, Cartografia, e até Matemática, e um espírito aberto e curioso pelos numerosos textos antigos aqui transcritos. Depois, temos de ter em conta que as novidades do livro são apoiadas em demoradas descrições analíticas, antes de se atingirem as conclusões que a autora apresenta. Às vezes parece que se está perante uma espécie de enigma policial, para cuja resolução é preciso percorrer sinuosos meandros.

Não sendo um livro fácil, ele é notável sob muitos pontos de vista, que esperamos ter deixado claramente assinalados Registe-se, ainda, uma espécie de inconfidência: Suzanne Daveau tinha já 85 anos quando a edição veio finalmente a público, tendo mantido uma vida intelectual preenchida e diversificada, ao mesmo tempo que preparava este difícil livro. Só alguém com uma sólida e variada preparação intelectual e muita determinação se poderia abalançar a uma obra de tal fôlego.

O que ficará por resolver no meio da complexidade do assunto? Atrevo-me a admitir que se podem colocar dúvidas quanto ao autor do códice. É uma interrogação que não se apoia em nenhuma outra hipótese (que não saberia avançar) mas nos próprios argumentos. Recorde-se que a própria Suzanne Daveau colocou outras hipóteses. Além disso, não será de estranhar que a figura de Francisco de Melo tenha sido tão poucas vezes mencionada a propósito de temas de História da Cartografia ou de História da Ciência, salvo no que se refere à sua presença na Junta de Elvas-Badajoz? O interesse que a sua obra parece começar a suscitar, de que é exemplo o investigador Henrique Leitão, não permite por enquanto concluir nada de seguro quanto à autoria do códice que foi oferecido ao cardeal D. Afonso.

Que os leitores possam enriquecer-se com a leitura deste livro, de que esta recensão apenas aflora alguns aspectos, fazendo chegar à autora novas ideias e sugestões, que perspectivas diferentes seguramente desencadeiam.

\section{AGRADECIMENTOS}

Deixa-se um reconhecimento à Publito - Estúdio de Artes Gráficas, Lda. Braga, pelo cuidado na impressão e nos acabamentos, cujo responsável faleceu entretanto, sem ter conseguido apreciar a sua última obra. A concepção gráfica do CD-Rom, do design e paginação do livro devem-se a André Luz.

\section{BIBLIOGRAFIA}

Alegria M F, Daveau S, Garcia J C, Relaño F (2007) Portuguese Cartography in the Renaissance. In Woodward D (ed.) The History of Cartography, III, Cartography in the European Renaissance, 1: 975-1068.
Ferreira A, Morais C, Silveira J, Girão A (1956-57) O mais antigo mapa de Portugal (c. 1561). Boletim do Centro de Estudos Geográficos, Coimbra, 12-13: 3-66; 14-15: 10-43. 